\title{
Improving Junior High School Teacher Ability in Designing Higher order Thinking (HOTS) Problems
}

\author{
Fridgo Tasman ${ }^{\# 1}$, Ahmad Fauzan ${ }^{\# 1}$ \\ 1 Jurusan Matematika Universitas Negeri Padang, Padang 25131, Indonesia \\ * Correspondence: fridgo_tasman@fmipa.unp.ac.id
}

Diterima 1 November 2019, Disetujui 21 Maret 2020, Dipublikasikan 31 Maret 2020

\begin{abstract}
The result of 2015 PISA (Program for International Students Assessment) test which placed Indonesia in the 65th position of 72 countries showed the importance to improve the level of students thinking ability. There are many ways to improve the students' thinking. One way to do that is by giving the students drill to solve higher order thinking problems. However, this solution is difficult to implement because designing HOTS (Higher Order Thinking Skills) problem is difficult for the teachers. Therefore, 20 junior high school mathematics teaches ware selected in order to give them training and workshop to improve their ability to design higher order thinking skills using action research methods. Three stages ware implemented in this training and workshop. First, introduction to HOTS, Second, designing HOTS Problems, and third, trying out and evaluating the test result. Product of the workshop are 30 mathematical problems in certain topic in which 15 of them are HOTS problems. To measure the effectiveness of the training and workshop, the result of pre-test and posttest were compared. Based on the data analysis, there was an increase of the ability of mathematics junior high school teachers to design problems to assess the higher order thinking skills.
\end{abstract}

Keywords - HOTS, Designing HOTS Problems, Junior High School Teacher.

\section{Pendahuluan}

Posisi Indonesia yang berada di peringkat 64 dari 72 negara pada hasil studi PISA di tahun 2015 (Program for International Students Assessment), menunjukkan pentingnya untuk meningkatkan kemampuan berfikir tingkat tinggi siswa. Hasil studi ini, melaporkan rendahnya kemampuan berfikir siswa di Indonesia. Kemampuan tersebut adalah 1) kemampuan memahami informasi yang kompleks, 2) kemampuan menganalisis teori dan kemampuan memecahkan masalah, 3) kemampuan menggunakan alat, memahami prosedur dan 4) kemampuan untuk melaksanakan investigasi.
Empat hal tersebut dikenal juga dengan istilah kemampuan berfikir tingkat tinggi atau higher order thinking skills (HOTS). Kemampuan ini sangat dibutuhkan sekali dalam era revolusi industri 4.0 saat ini.

Namun, banyak hasil studi menunjukkan rendahnya kemampuan berfikir tingkat tinggi siswa. [1], [2], [3], [4]. Di Sumatera Barat sendiri, kemampuan berfikir tingkat tinggi ini juga rendah [5]. Salah satu faktor yang menjadi penyebabnya adalah para guru belum mengenal dengan baik apa itu kemampuan berfikir tingkat tinggi. Kondisi serupa juga terjadi di kota Padang. Berdasarkan wawancara dengan beberapa guru matematika tingkat SMP di kota Padang, 
terungkap bahwa para guru umumnya tidak terbiasa dalam merancang soal-soal untuk mengases kemampuan berfikir tingkat tinggi siswa. Para guru pada umumnya menggunakan soal-soal yang telah ada pada buku teks. Dimana soal-soal pada buku teks tersebut pada umumnya hanya berada pada level kognitif rendah (pengetahuan/C1, pemahaman/C2, dan aplikasi/C3) sedangkan kemampuan berfikir tingkat tinggi berada pada level kognitif analisis/C4, evaluasi/C5 dan mencipta/C6. Hal ini menyebabkan para siswa di sekolah sangat jarang sekali mendapatkan persoalan tipe HOTS ini.

Berdasarkan uraian masalah tersebut, maka dirasakan sangat diperlukan diadakannya program peningkatan kemampuan guru dalam merancang soal-soal untuk dapat mengases kemampuan berfikir tingkat tinggi (HOTS) di kota Padang dengan mitra guru-guru matematika SMP kota Padang yang tergabung dalam MGMP Matematika Kota Padang.

\section{Solusi/Teknologi}

Berdasarkan permasalahan yang di hadapi oleh para guru matematika SMP kota Padang yang tergabung dalam MGMP matematika Kota Padang yang telah di paparkan di bagian pendahuluan, maka beberapa alternatif solusi yang dilaksanakan adalah sebagai berikut;

1. Menambah wawasan para guru matematika SMP tentang HOTS.

2. Meningkatkan keterampilan guru dalam merancang soal-soal untuk dapat mengases HOTS.

\section{Hasil dan Diskusi}

Sebelum kegiatan pelatihan dan workshop dilaksanakan para guru diberikan pretes. Pada pretes tersebut para guru diberikan 8 pertanyaan untuk dijawab. Kedelapan pertanyaan tersebut secara garis besar dapat dibagi kedalam tiga bagian yaitu 1) Pengetahuan tentang HOTS. 2) Keterampilan Merancang Soal HOTS, dan 3) Kemampuan menyelesaikan persoalan HOTS.

Berdasarkan hasil pretes, pada umumnya pengetahuan guru tentang HOTS masih rendah.
Hal ini ditunjukkan hanya $30 \%$ dari para guru yang dapat menghubungkan kemampuan berfikir tingkat tinggi dengan level kognitif pada Bloom. Sedangkan kemampuan para guru merancang soal sudah baik. Akan tetapi kemampuan guru merancang soal-soal HOTS masih sangat rendah. Hal ini ditunjukkan dengan $90 \%$ para guru dapat merancang soal. Akan tetapi soal yang telah dirancang oleh guru pada umumnya berlevel rendah, lower order thinking (LOTS), hanya 60\% guru mampu merancang soal tipe HOTS. Sedangkan kemampuan guru dalam menyelesaikan persoalan HOTS baik. Hal ini ditunjukkan dengan 90\% guru dapat menjawab persoalan HOTS dengan benar.

Setelah pretes dilaksanakan, para peserta kegiatan diberikan pengetahuan tentang HOTS yang mengacu kepada taksonomi bloom dan revisinya yang dapat dilihat pada gambar 1 .

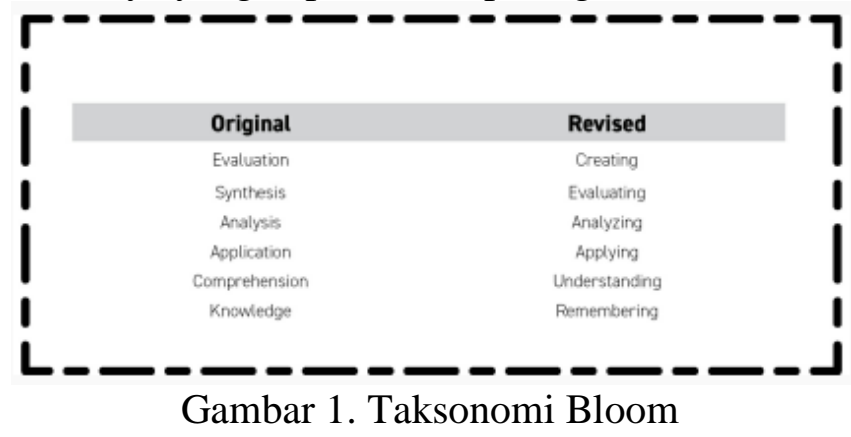

Guru-guru peserta PKM juga diberikan contohcontoh soal HOTS yang disampaikan oleh narasumber kegiatan. Berikut beberapa contoh soal yang diberikan pada saat kegiatan workshop dan pelatihan;

\section{- Evaluating}

Seorang Ibu membagi sebuah pizza kepada 3 orang anaknya. Anak pertama memperoleh $1 / 4$ bagian, anak ke dua memperleh $1 / 3$ bagian, dan anak ke tiga memperoleh 2/5 bagian. Apakah Ibu sudah adil dalam membagi? Jelaskan jawabanmu!

Kepada para guru penekanan soal tersebut adalah bagaimana para siswa mengevaluasi pernyataan adil dan upaya dalam menjustifikasi jawaban untuk menyakinkan orang lain bahwa kesimpulan yang di dapat adalah benar berdasarkan pengetahuan yang di dapat dalam konsep membandingkan pecahan. 


\section{- Creating}

Tulislah sebuah soal cerita yang melibatkan pecahan dengan penyebut yang berbeda !

Kepada para guru penekanan soal tersebut adalah bagaimana para siswa berupaya menciptakan permasalahan yang sesuai dengan batasan masalah.

Setelah para guru diberikan contoh-contoh persoalan tentang HOTS. Para guru diminta merancang soal-soal yang HOTS berdasarkan kelas yang diajarkan di sekolah. Guru-guru tersebut merancang soal-soal HOTS secara berkelompok untuk di presentasikan dan di validasi bersama. Pada saat kegiatan para guru dibagi menjadi lima kelompok yang terdiri dari 2 kelompok kelas VII dan IX dan satu kelompok kelas VIII. Masing masing kelompok membuat satu soal dengan berdasarkan level kognitif bloom.

Berikut ini adalah soal-soal hasil rancangan guru yang di urut berdasarkan level kognitif bloom yang direvisi;

- Rancangan soal kelas VII versi 1 Topik Bilangan

1. Tuliskanlah definisi dari bilangan prima dan berikan contohnya!

2. Letakanlah bilangan-bilangan berikut pada suatu garis bilangan!

\section{a. -4 dan 2}

b. -6 dan 0

3. Pada percobaan Fisika seorang siswa melakukan pengukuran suhu pada sebongkah es. Suhu es tersebut mula-mula $-50^{\circ} \mathrm{C}$ setelah dipanaskan es berubah menjadi air yang bersuhu $60^{\circ} \mathrm{C}$. Berapakah kenaikan suhu es tersebut hingga menjadi air? Jelaskan Jawabanmu!

4. Dalam kegiatan bakti sosial panitia menerima sumbangan beras dari 3 orang warga, Warga pertama menyumbang 22 $\mathrm{kg}$, warga kedua $4 \mathrm{~kg}$ lebih dari warga pertama dan warga ketiga memberikan 2 kali lipat dari warga kedua. Jika masingmasing warga penerima sumbangan memperoleh 2 sampai $3 \mathrm{~kg}$. Maka berapa banyak warga maksimum yang mendapatkan beras? Jelaskan jawabanmu!
5. Pada sebuah tes yang terdiri dari 40 butir soal, setiap jawaban benar diberi skor 2,jawaban salah skor -1 dan tidak dijawab skor 0. Budi menjawab 34 soal dan 29 soal diantaranya benar, sementara itu Andi tidak menjawab 4 soal dan 28 dijawab benar. Apakah skor Budi dan Andi akan sama? jelaskan jawabanmu...!

6. Pak Amin mempunyai 20 ekor ayam,16 ekor itik,dan 12 ekor angsa. Ia akan memasukkan ternak ini kedalam beberapa kandang dengan jumlah masing-masing ternak dalam tiap kandang sama. Berapa kandang yang harus dibuat pak Amin? Jelaskan jawabanmu !

- Rancangan soal kelas VII versi 2 Topik Pecahan

1. Perhatikanlah gambar berikut!

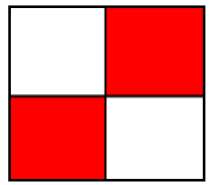

Tentukanlah nilai pecahan yang merepresentasikan daerah yang diarsir!

2. Urutkanlah pecahan berikut dari yang

$$
\frac{1}{2}, \quad \frac{1}{3}, \quad \frac{2}{5}, \quad \frac{3}{8}
$$

terkecil!

3. Seorang ibu memiliki stok $2 \frac{1}{3} \mathrm{~kg}$ beras, untuk persediaan ia membeli lagi $6 \frac{1}{4} \mathrm{~kg}$ beras. Setelah dimasak $1 \frac{1}{2} \mathrm{~kg}$, berapa persediaan beras ibu yang tinggal?

4. Pak Rudi mempunyai sebidang lahan, $\frac{1}{3}$ bagian ditamani jagung, $\frac{1}{4}$ bagian ditamani sayuran dan sisanya ditanami cabe dengan luas $200 \mathrm{~m}^{2}$. Berapakah luas lahan yang dimiliki pak Rudi?

5. Kakak memiliki pita sepanjang $\frac{1}{2} \mathrm{~m}$, kemudian ia membeli lagi pita yang sama sepanjang $\frac{3}{4} \mathrm{~m}$. Pita tersebut akan dibagikan kepada 3 orang adiknya. Adik 
ke-I mendapatkan $\frac{1}{3}$ bagian, Adik ke-II mendapatkan $\frac{3}{10}$ bagian, dan sisanya diberikan kepada adik yang ketiga. Siapakah diantara ketiga adiknya yang mendapatkan pita paling panjang? Jelaskan pendapatmu!

6. Tuliskan sebanyak mungkin pecahan yang menghasilkan nilai yang sama dengan $\frac{4}{5}$ !

- Rancangan soal kelas VIII Topik Pola Bilangan

1. Lengkapilah gambar berikut ini;
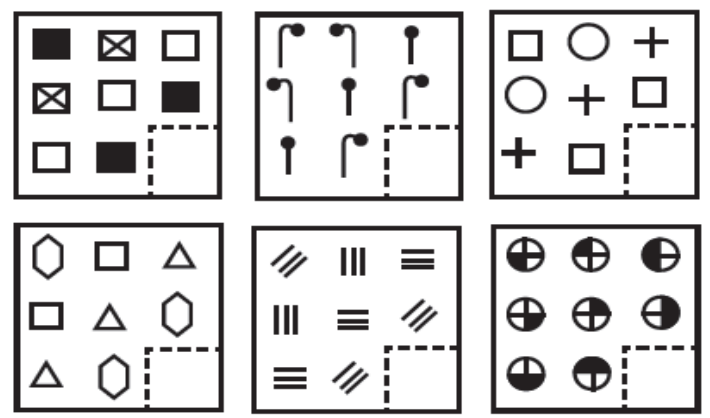

2. Tentukanlah tiga bilangan berikutnya dari barisan bilangan $\frac{3}{4}, 1, \frac{4}{3}, \frac{16}{9}$ !

3. Perhatikan susunan lantai dari beberapa persegi yang diarsir seperti pada gambar

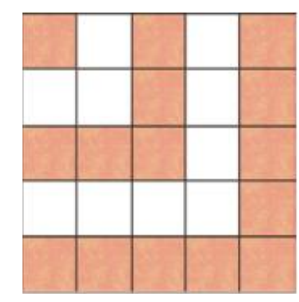

susunan persegi tersebut membentuk sebuah pola tertentu. Berapakah banyak persegi yang diarsir pada pola ke-7?

4. Ibu Lily membagikan uang sebesar Rp 200.000,00 kepada 5 orang anaknya. Semakin besar usia anak,maka semakin banyak uang yang akan dia terima. Jika selisih uang yang diterima oleh setiap dua orang anak yang usianya berdekatan adalah $\mathrm{Rp} 10.000,00$,dan sibungsu menerima uang paling sedikit, maka tentukanlah uang yang diterima anak ketiga!
5. Azzam mengisi liburan sekolahnya untuk bekerja ditoko, sebelum bekerja dia diminta memilih antara diberi gaji sebesar Rp 75.000,00 perhari selama seminggu atau diberikan gaji sebesar Rp 10.000,00 pada hari pertama dan bertambah dua kali lipat tiap harinya selama seminggu. Manakah pilihan terbaik yang harus dipilih Azzam agar mendapat kan gaji yang maksimal? Jelaskan jawabanmu !

6. Perhatikan pola dibawah ini:

$$
\begin{array}{llllll}
1 & & & & & \\
2 & 3 & & & & \\
4 & 5 & 6 & & & \\
7 & 8 & 9 & 10 & & \\
11 & 12 & 13 & 14 & 15
\end{array}
$$

a. Tentukanlah bilangan pertama pada baris ke -10 dan ke- 20, jelaskan jawabanmu !

b. Apakah kamu dapat menentukan bilangan pertama pada baris ke-n, jelaskan jawabanmu!

- Rancangan soal kelas IX versi 1 Topik Bilangan Berpangkat

1. Apakah arti dari $2^{3}$ ?

2. Berapakah hasil dari $3^{2}+5^{2}$ ?

3. Apakah ada suatu kubus yang memiliki volume $729 \mathrm{~cm}^{3}$ ?, Jika ada, berapakah panjang rusuk kubus tersebut !

4. Perhatikanlah gambar rubik berikut !

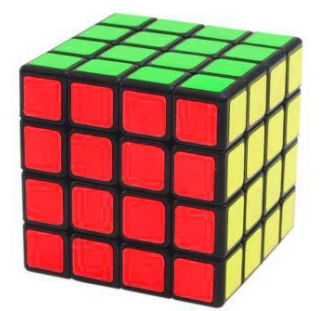

Tentukanlah ;

a. Banyak kubus-kubus kecil penyusun rubik tersebut yang diberi cat tiga sisinya dengan warna berbeda 
b. Banyak kubus-kubus kecil penyusun rubik tersebut yang diberi cat dua sisinya dengan warna berbeda

c. Banyak kubus-kubus kecil penyusun rubik tersebut yang satu sisinya diberi cat

d. Banyak kubus-kubus kecil penyusun rubik tersebut yang tidak terkena cat

Jelaskan jawabanmu !

5. $-1^{100}=1$, benar atau salahkan pernyataan tersebut! Jelaskan jawabanmu!

6. Carilah sebanyak mungkin pasangan bilangan berpangkat yang jika dikalikan hasilnya 81 !

- Rancangan soal kelas IX versi 2 Topik Bentuk Akar

1. Tuliskanlah beberapa bentuk akar yang kamu ketahui !

2. Sederhanakanlah bentuk akar dari $\sqrt{12}$ ?

3. Kebun yang berbentuk persegi panjang, memiliki panjang $\sqrt{1200} \mathrm{~m}$ dan lebar $\sqrt{300} \mathrm{~m}$. Tentukanlah panjang diagonal dari bentuk akar tersebut !

4. Perhatikanlah gambar berikut !
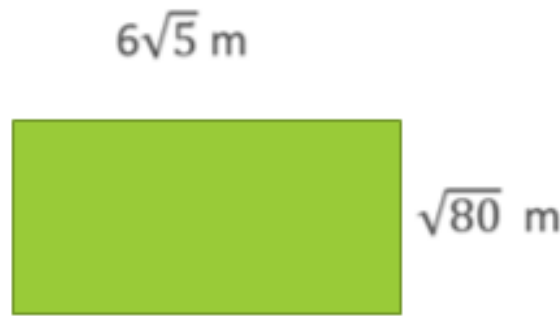

Gambar di atas merupakan gambar sebuah kolah yang akan dipagari dengan kawat sepanjang $75 \sqrt{5} \mathrm{~m}$, Apakah kawat tersebut cukup untuk mengelilingi 4 kali putaran kolam? Jelaskan pendapatmu !

5. Pak Adi akan membeli sebidang tanah untuk dibuat toko, ia menemukan dua wilayah yang cocok untuk pertokoannya. Di wilayah A, ia menemukan sebidang tanah yang berbentuk persegi panjang berukuran $15 \sqrt{3} m \times 10 \sqrt{3} m$ dengan harga Rp. 1.100.000,00 untuk setiap $\mathrm{m}^{2}$, Sedangkan di wilayah $B$, ia menemukan sebidang tanah berbentuk persegi berukuran $14 \sqrt{3} \mathrm{~m}$ dengan harga per $\mathrm{m}^{2}$ Rp. 900.000,00. Jika pak Adi menganggarkan Rp. $\quad 500.000 .000,00$ untuk pertokoan tersebut. Bantulah pak Adi menentukan pilihan tanah yang akan di belinya ! jelaskan alasanmu !

6. Tuliskan sebanyak mungkin, dua bentuk akar yang hasil pembagiannya adalah $\sqrt{2}$ !

Setelah rancangan soal di buat, para guru dilatih untuk merancang rubrik penskoran untuk persoalan yang telah mereka rancang. Kemudian soal-soal tersebut di cobakan dan di ujikan kepada para siswa mereka di sekolah.

Berdasarkan catatan lapangan kegiatan pelatihan dan workshop di identifikasi bahwa, kesulitan guru dalam merancang soal, salah satunya di sebabkan oleh kurangnya sumber belajar. Para guru mengakui agak kesulitan mencari buku-buku referensi untuk merancang soal HOTS. Untuk itu tim pengabdian kepada masyarakat (PKM) menyarankan agar guru dapat merancang soal mereka sendiri seperti yang dilakukan pada pelatihan dan workshop yang diadakan. Selain itu, para guru mengakui bahwa kesulitan dalam merancang soal adalah menentukan level soal. Untuk itu, tim menyarankan agar para guru memperhatikan indikator soal dan memperhatikan perbedaan level kognitif yang ada pada taksonomi Bloom.

Pada akhir kegiatan, para guru diberikan postes, yang menanyakan tiga aspek yang sama dalam pretes. Perbandingan hasil pretes dan postes yang diberikan dapat dilihat pada tabel 1 .

\begin{tabular}{|l|l|l|l|}
\hline & $\begin{array}{l}\text { Pengetahuan } \\
\text { Tentang } \\
\text { HOTS }\end{array}$ & $\begin{array}{l}\text { Keterampilan } \\
\text { Merancang } \\
\text { Soal HOTS }\end{array}$ & $\begin{array}{l}\text { Kemampuan } \\
\text { menyelesaikan } \\
\text { persoalan } \\
\text { HOTS }\end{array}$ \\
\hline Pretes & $30 \%$ & $60 \%$ & $90 \%$ \\
\hline
\end{tabular}




\section{\begin{tabular}{l|l} 
Postes & $90 \%$ \\
\hline
\end{tabular} $85 \%$ $92 \%$ \\ Tabel 1. Perbandingan hasil pretes dan postes}

Berdasarkan Tabel 1, dapat dilihat bahwa terjadi peningkatan terhadap ketiga aspek yang dilihat dalam program kemitraan masyarakat yang dilaksanakan.

Pengetahuan guru tentang HOTS dan kemampuan merancang soal HOTS pada awalnya sebelum diadakanya tranning dan workshop masih tergolong rendah, namum kemampuan guru dalam menjawab persoalan sudah baik. Pada awalkan pengetahuan guru tentang HOTS hanya didasarkan oleh pemahaman guru akan kesulitan soal, tanpa melihat batasan berdasarkan level kemampuan yang ada pada taksonomi bloom. Setelah penjelasan yang comprehensif dari narasumber tentang apa itu HOTS terlihat adanya peningkatan pengetahuan guru tentang HOTS. Selain itu, penjelasan narasumber kegiatan yang baik tentang bagaimana merancang soal HOTS mengakibatkan meningkatnya kemampuan guru dalam merancang soal tipe HOTS.

\section{Kesimpulan}

Kegiatan program kemitraan masyarakat tentang peningkatan kemampuan guru dalam merancang soal-soal untuk mengases kemampuan berfikir tingkat tinggi (HOTS) membawa dampak yang cukup signifikan terhadap peningkatan wawasan mitra, yang dalam hal ini adalah guruguru matematika yang tergabung dalam MGMP Matematika SMP Kota Padang.

\section{Ucapan Terima Kasih}

Ucapan terima kasih diberikan kepada Universitas Negeri Padang, yang telah mensponsori kegiatan PKM ini melalui skim kegiatan PKM 2019 pendanaan PNBP UNP.

\section{Pustaka}

[1] G. A. M. Saido, S. Siraj, A. B. Nordin, and O. S. Al-Amedy, "Teaching strategies for promoting higher order thinking skills: A case of secondary science teachers," MOJEM Malaysian Online J. Educ. Manag., vol. 3, no. 4, pp. 16-30, 2017.

[2] N. M. Tajudin and M. Chinnappan, "The Link between Higher Order Thinking Skills, Representation and Concepts in Enhancing TIMSS Tasks.," Int. J. Instr., vol. 9, no. 2, pp. 199-214, 2016.

[3] S. Saragih, E. E. Napitupulu, and A. Fauzi, "Developing Learning Model Based on Local Culture and Instrument for Mathematical Higher Order Thinking Ability," Int. Educ. Stud., vol. 10, no. 6, p. 114, 2017.

[4] L. Leonard, "Kompetensi tenaga pendidik di indonesia: Analisis dampak rendahnya," Form. J. Ilm. Pendidik. MIPA, vol. 5, no. 3, pp. 192 201, 2015.

[5] F. Tasman, "IMPROVING PAYAKUMBUH ELEMENTARY TEACHERS' ABILITY IN DESIGNING MATHEMATICAL HIGHER ORDER THINKING SKILLS PROBLEMS," Pelita Eksakta; Vol 2 No 1 Pengabdi. MasyarakatDO - 10.24036/pelitaeksakta/vol2iss1/61 , Jul. 2019. 